\title{
Study on Late Bronze Age Potteries of Shahrak-e Firouzeh, Neyshabur, Iran by XRD and XRF
}

\author{
Mohammad Hossein Rezaei ${ }^{\mathrm{a}}$, Hassan Basafa ${ }^{\mathrm{a}}$, Parasto Masjedi Khak ${ }^{\mathrm{a}^{*}}$, Mahya Azar ${ }^{\mathrm{a}}$ \\ ${ }^{a}$ Department of Archaeology, University of Neyshabur, Adib Blvd, Neyshabur, Khorasan-e Razavi, Iran
}

\section{ARTICLE INFO}

\section{Article history:}

Received: $9^{\text {th }}$ August 2017

Accepted: $24^{\text {th }}$ April 2018

DOI: http://dx.doi.org/ 10.24916/iansa.2018.1.2

\section{Key words:}

Pottery

XRD

XRF

Shahrake Firouzeh

Bacteria Margiana Archaeological Complex

\section{A B S TR A C T}

During excavations of the Shahrake Firouzeh site, much evidence of the Bactria Margiana Archaeological Complex or Amu Darya Civilization has been found. Such evidence is spread across northern Iran, northern Afghanistan, eastern Turkmenistan, southern Uzbekistan, and western Tajikistan. In the present study, pottery samples from the Firoozeh town area were studied using XRD and XRF methods. Using the XRF method and Dplot Software, 15 samples were studied and the data evaluated by analyzing the ratio of various components. The results of the study show that the dominant clay source of the pottery samples existed in the same region, while two other clay subsources from adjoining regions were also identified.

\section{Introduction}

Because of its continuous and abundant production, pottery has always been associated with the alterations and innovations of its shapes and patterns. Such changes happen partly due to the internal intricacies of cultures over time and partly due to the cultural and economic ties with neighbouring and distant societies. On the other hand, for various reasons, such as being a merchandise that can be exported as well as its use in transporting other goods, pottery can be considered as the best cultural data for the recognition of ethnic groups and societies. Pottery is so important in studying the relationship between the different cultural units of a region on the one hand, and trans-regional cultures on the other, that no other cultural data in archaeology could reach the same level of significance. Thus pottery should be studied not only from various aspects but also from different perspectives. The samples that were discovered across the ancient sites of Iran show the connection of this art to culture, economy, and religion; moreover, they display the taste and virtue of the potters (Majidzadeh, 1991).

*Corresponding author. E-mail: parestomasjedi@yahoo.com
Using chemical and physical methods, archaeometry is a great help to archaeologists and art historians. Its use in determining the origins of archaeological findings is one of the most modern approaches in the field of archaeometry. This field of science presents archaeological data, or related phenomena, as quantitative, measurable or qualitative data. Among the laboratory methods, two relatively quick and easy ones that have helped the fields of archaeology and art history are the XRF and XRD methods. XRF (X-ray fluorescence) involves a device for measuring the wavelength and intensity of fluorescence waves released from the atoms of a sample through which the amounts of the sample's constituent elements can be recognized (Talai et al., 2009). As a rapid mechanical analysis tool, this device is widely used in many laboratories around the world (Sabzali et al., 2010). The XRD (X-ray diffraction) test is also used to measure atomic plate spacing; in other words, to identify the material structure and ultimately determine the minerals within the pottery. For the XRD test, the pottery sample must be crushed into powder and then placed in the device. The device automatically analyzes the sample and records the analysis results in the computer connected to it (Talai et al., 2009). 


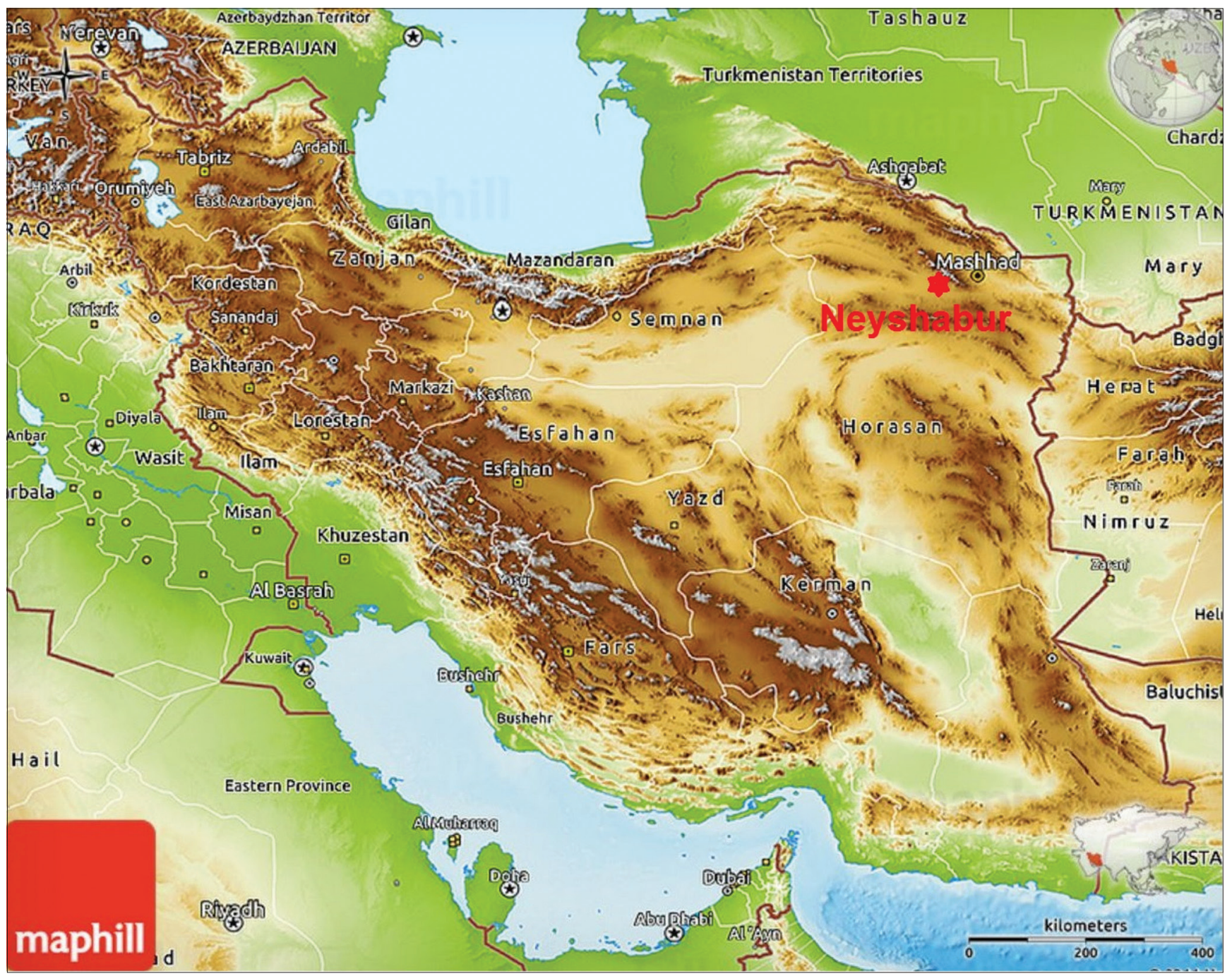

Figure 1. Geographic position of Neyshabur city, northeast of Iran (map by authors).

In this regard, such use of laboratory methods and techniques enables more accurate and reliable results to be obtained. There exist several techniques for the identification of the materials and elements that form archaeological findings and through which a broader range of knowledge and understanding of the rocks, pottery, their material, application, history, age, style, identity, origin, manufacturing process and technology used, source, and trade routes utilised, can be gained. Laboratory research on the physical characteristics of prehistoric pottery is one of the efficient non-descriptive methods that aim to identify such technical features as method of production, the presence or absence of vegetation, type of soil grading, type of tempering, and the quality of baking; moreover, the empty spaces in the body of the clay, which is related to the general quality of the clay, can be determined (Talayi, Yari, and Taqizoqi, 2009).

\section{Area under Study}

Neyshabur town is located in the Neyshabur plain in the Razavi Khorasan Province in northeast Iran (Figure 1).
This area has a special geographic and climatic situation and, due to its location on the Silk Road, has attracted so many people throughout history that much archaeological evidence has been found from the prehistoric, historical, and Islamic era in this region. Neyshabur plain is located on the slopes of the Alborz Mountains and Binaloud Heights that provide rich water sources to this plain. Water abundance has created numerous habitats in different parts of the slopes of these mountains and the Shahrake Firouzeh site is one of the most significant ones (Figure 2). This area with a latitude of 36 degrees and 12 minutes, longitude of 58 degrees and 47 minutes, and with an average height of 1250 metres above sea level is located in the Neyshabur plain (Basafa et $a l ., 2014)$. This area is named after the newly-constructed residential complex in the western part of the present-day Neyshabur city which is located in the eastern part of the Faroub Ruman River. As the most important water stream of the city, this river originates from the highlands of the Binaloud Heights. It is also one of the independent rivers of the Markazi Desert sub-areas that floods in the rainy season. Because of the slopes of the plain, with the flood of the Farub 
Figure 2. Position of Shahrake Firouzeh in Neyshabur plain (map by authors).

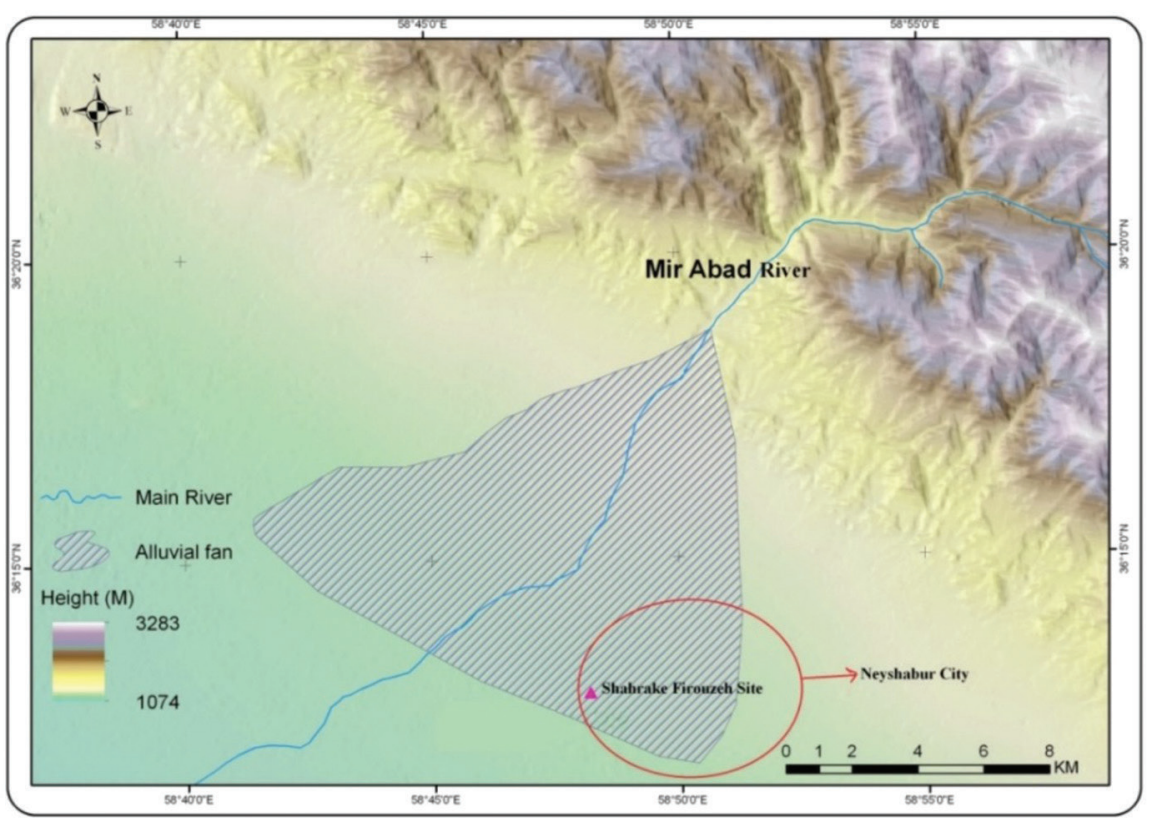

Ruman and other rivers, a high volume of alluvium has been deposited in the plain in a long-term process. The dimension of the Shahrake Firouzeh site is unclear because it is buried under alluvial deposits and according to preliminary studies, a large part of it lies under the residential areas of Neyshabur (Basafa et al., 2014). Generally, based on the excavations, the Shahrake Firouzeh site area represents Bronze and probably Iron Age cultures in the region; besides, the findings about the cultural materials point to the existence of a culture called the Bacteria Margiana Archaeological Complex (BMAC) (Basafa, 2014). This culture appeared in the second half of the $2^{\text {nd }}$ millennium $B C$, in the Merv region, which is located in the southeast of today's Turkmenistan, changes occurring in the human population during this period (Sarianidi, 1998). The time span starts from 2300 or 2200 BC and continues until $1700 \mathrm{BC}$. The most important cultural materials were prestigious goods made of chlorite or steatite, metal objects made with casting techniques, marble columns, steatite stamps, plates made in Late Serie style, and special types of pottery whose illustrations related specifically to this culture. The obtained artefacts show the regional and trans-regional interactions of Shahrake Firouzeh with its neighbouring areas, such as Merv, Balkh, southern Turkmenistan, and Iran. Findings such as pieces of slag, metals, furnace waste, pottery furnaces, etc., show a dynamic and stable settlement with extensive industrial activities (Basafa, 2014). The BMAC potteries are related to the Late Bronze Age, which are often found in a burial context in the Shahrake Firouzeh site.

Neyshabur's geological zone consists of the three eras, starting with the Paleozoic, then Mesozoic and Cenozoic. The oldest geological formations of the region is related to the Precambrian era that consists of calc, schist and phyllite (Shorm) and dolomite crystalline (Soltanieh) that outcrops in the north eastern parts. Formations of the first geological period are located in the northern parts of the plain in the northern Binaloud Heights that include quartzite (Lalun) sandstones, dolomite, dolomitic limestone, and shale (Mila), marl limestone (Niur), limestone and dolomite (Bahram), and crystallized quartzite. The second geological formations consist of Mashhad phyllite, light grey limestone, pale golden (Jurassic) limestone, and coloured mélanges ('mixture of colours'). The Jurassic black schist has spread across the $250 \mathrm{~km}^{2}$ of the Binaloud Heights to the Mashhad area. In the northwestern and southern heights, the tuffs and conglomeration formations can be seen in green. The igneous rocks of the area have plenty of gaps due to the decomposition of the feldspars, which provide a source for groundwater storage. Miocene formations exist in the form of marl-gypsum and salty sediments along with sandstone with a variety of colours. These formations have spread across the northern margins and partly onto the southern parts of the plain. The deposits of the third era of geology that are widely distributed in the region outcrop in the slopes of the central and southern heights. These formations consist of sandstones, shale, conglomerate, marl, and igneous (often exterior) rocks (Figure 3).

The Quaternary formations consist of terraces, alluvial fans, shifting sands, and alluvial deposits. In addition, scientists believe that some of the volcanic formations of this region are also of the Pleistocene Age. In terms of tectonics, the Khorasan Province is generally divided into four distinct regions: the Kopet-Dagh area, the Eastern region of Central Iran, the Lut region, and finally the Eastern part of the Iran mountains. Neyshabur city is located in the tectonic region of the eastern part of Central Iran.

The Neyshabur plain has special natural and geographical features and one of the reasons for its importance is its connective role as a result of its city's location on the commerce route of the Silk Road from earliest times. 


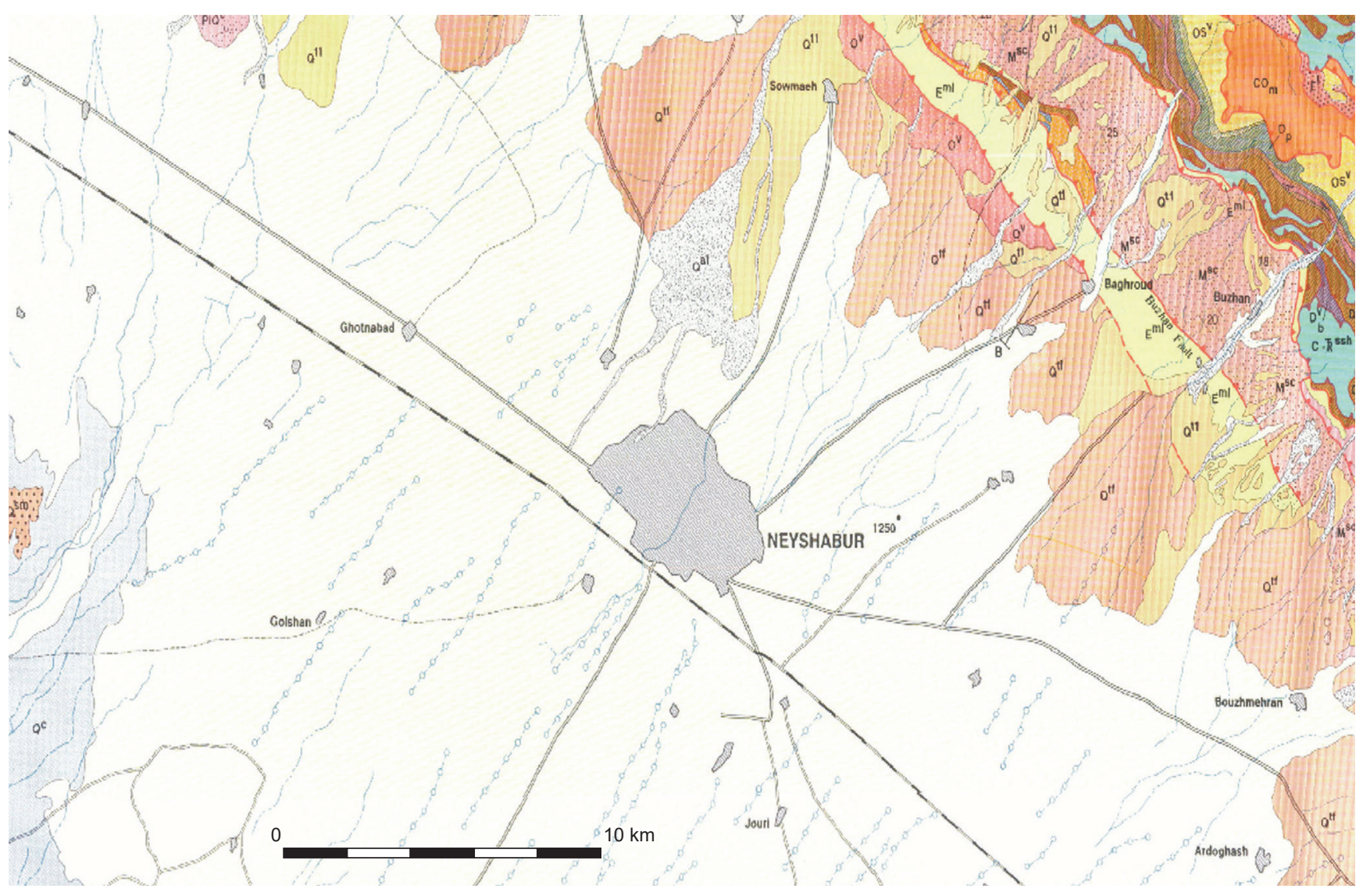

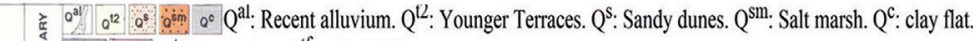

0 政

ô a $^{\text {t1 }} Q^{\text {tl }}:$ Older tarraces.

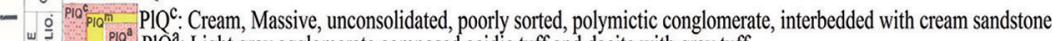

Plo $\mathrm{PIQ}$ : Light gray agglomerate composed acidic tuff and dacite with gray tuff.

O

$N^{2} \frac{0}{\frac{m}{2}} \mathrm{~m}^{\mathrm{m}}$ quartzite and andesite pebbels, interbedded with red medium bedded sandstone, siltstone and marl

$\mathrm{N} \sim \mathrm{\delta}_{0} 0_{0} 0^{\circ} \mathrm{O}^{\mathrm{cS}}$. Light red, medium bedded, polymctic conglomerate with intercalation of pink feldespatic litarenite and red marl.

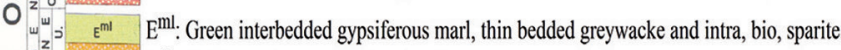

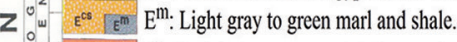

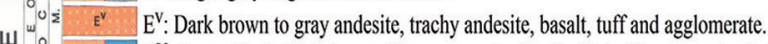

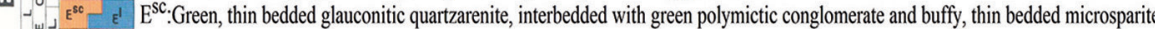

$\mathrm{O}_{0} \quad \mathrm{PE}^{\mathrm{C}}$ :Light red, massive, poorly sorted, poorly rounded, polymictic conglomerate composed of limestone,quartzarenite

PV: light green to red dacit and dacitic andesite, tuff, agglomerate.

O. ग J Jight gray to brown, thick to medium bedded intrabiomicrosparite

W J J Gray thin bedded marl interbedded with light gray medium bedded limestone

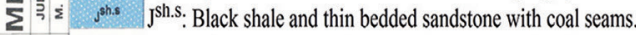

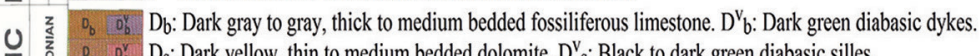

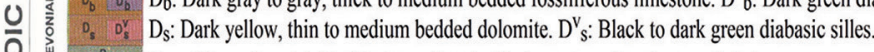

N $\quad D_{p} \quad D_{p}$ : white red to pinkish,thin to medium bedded quartarenite arkose and shale.

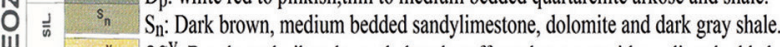

U. $\quad \mathrm{s}^{\mathrm{v}} \quad \mathrm{OS}^{\mathrm{V}}$ : Basalt, andesibasalt, trachybasalt, tuff, agglomerate with medium bedded graywack and volcanogenic conglomerate.

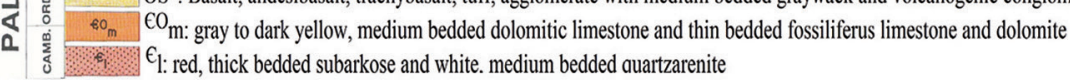

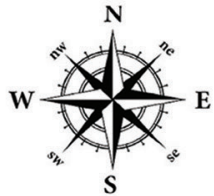

Figure 3. Geological map of the region under study (map from Iranian geology org) 
However, due to the active and dynamic geomorphological conditions of the region and continuous flood flows, the prehistoric settlements of the area were displaced and buried under alluvial deposits. The Shahrake Firouzeh site is one of the prehistoric areas dating back to the Late Bronze Age that was established on the sidelines of an alluvial fan. Generally, alluvial fans have provided appropriate conditions for the establishment of human settlements (Figure 3) around the world from prehistoric times, which is due to their underground water-rich aquifers, the alluvial fan's gentle slopes, the fertility of the soil due to sedimentation, and the existence of water streams that provide the water needed for drinking, farming, and such craft industries as making pottery (Gillmor et al., 2009; 2011).

\section{Aims and Research Method}

This study uses the XRF and XRD laboratory methods in order to determine the composition of the potteries found in the Shahrake Firouzeh site. These potteries relate to the Late Bronze Age (BMAC Culture) and they were often obtained from the burial areas. This research investigates the New Bronze Age potteries of the Shahrake Firouzeh site based on laboratory methods for the first time: a step towards recognizing the clay sources used for pottery production at the Shahrake Firouzeh site and determining the cultural and commercial ties of this town. Ultimately, it should be pointed out that the purpose of these experiments on the samples is to understand if the potteries were produced locally or were imported into the Shahrake Firouzeh through trans-regional transactions.

With the XRF and XRD laboratory methods, 15 pottery samples were analyzed from trenches X \& XII. The research samples were selected from a set of potteries with a specified chronological and stratigraphic context. Three samples were analyzed by the XRD method and 15 samples by XRF. The statistical analysis of the laboratory findings were based on the spectroscopy of the chemical elements and their quality and quantity. After the sampling and performing of relevant tests, the data were analyzed so as to ascertain if the potteries were of local production or imported.

Fragments of about $1 \mathrm{~cm}^{2}$ were removed from each shard and abraded using a silicon carbide burr in order to remove surface treatments (e.g. glaze, slip, paint) and adhering soil, thereby reducing the risk of measuring contamination. The specimens were washed in deionized water and allowed to dry in the laboratory.

\section{Results}

\subsection{XRD}

The X-ray diffractometer was originally designed for examining powder samples. However, the diffractometer is today more often used for examining samples of crystalline aggregates other than powder. Also polycrystalline solid samples and even liquids can be examined. Importantly, a sample should contain a large number of tiny crystals (or grains) which randomly orient in three-dimensional space because standard X-ray diffraction data are obtained from powder samples of perfectly random orientation (Leng, 2008, p.61). The key characteristic of XRD is its ability to identify crystalline minerals. The primary use of the powder XRD method has been the identification of clay minerals in pottery in order to characterize pottery types and to investigate sources for raw materials (Pollard et al., 2007, p.120). XRD also allows the examination of firing

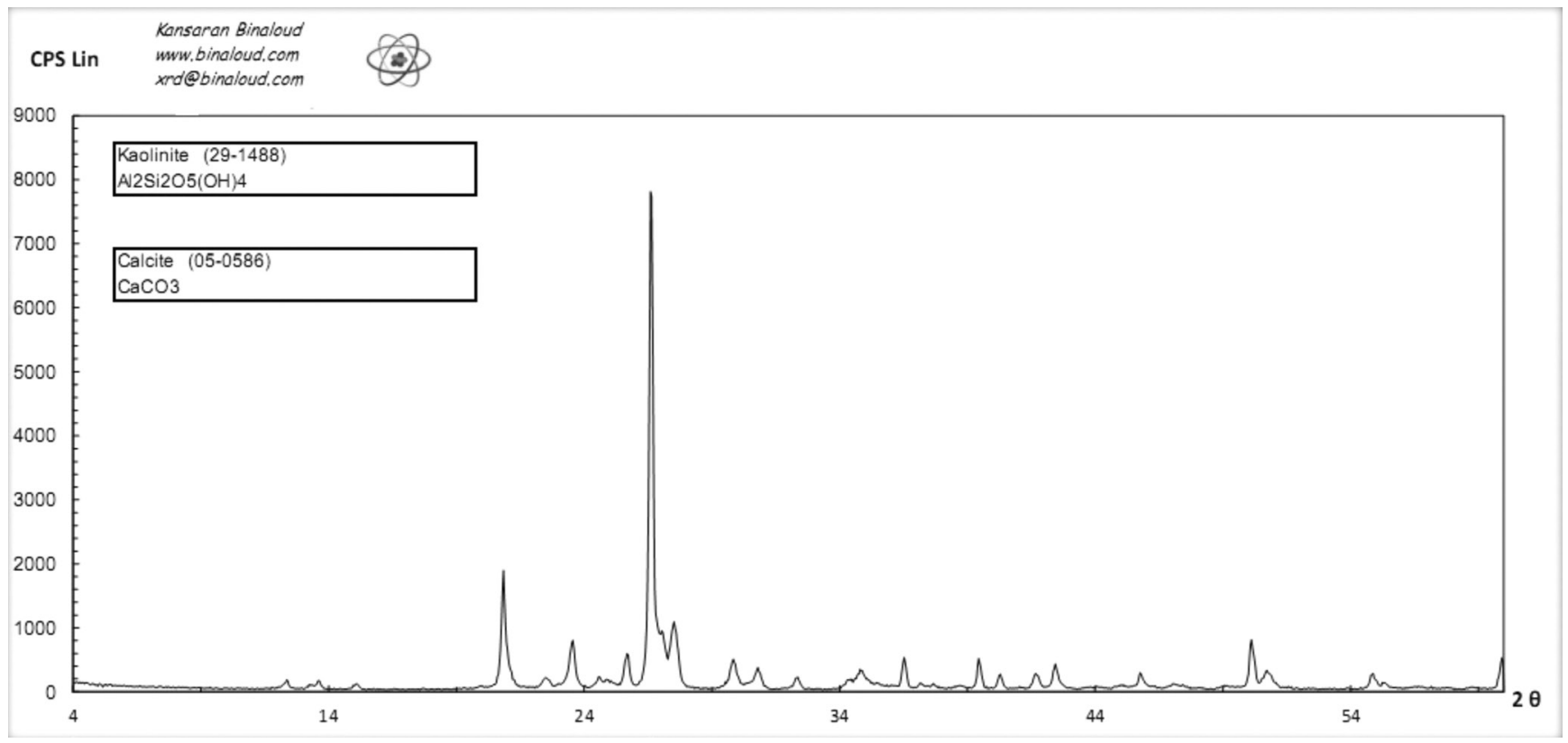

Figure 4. Sample No.1 XRD spectra diagram, showing clay and calcite minerals. 


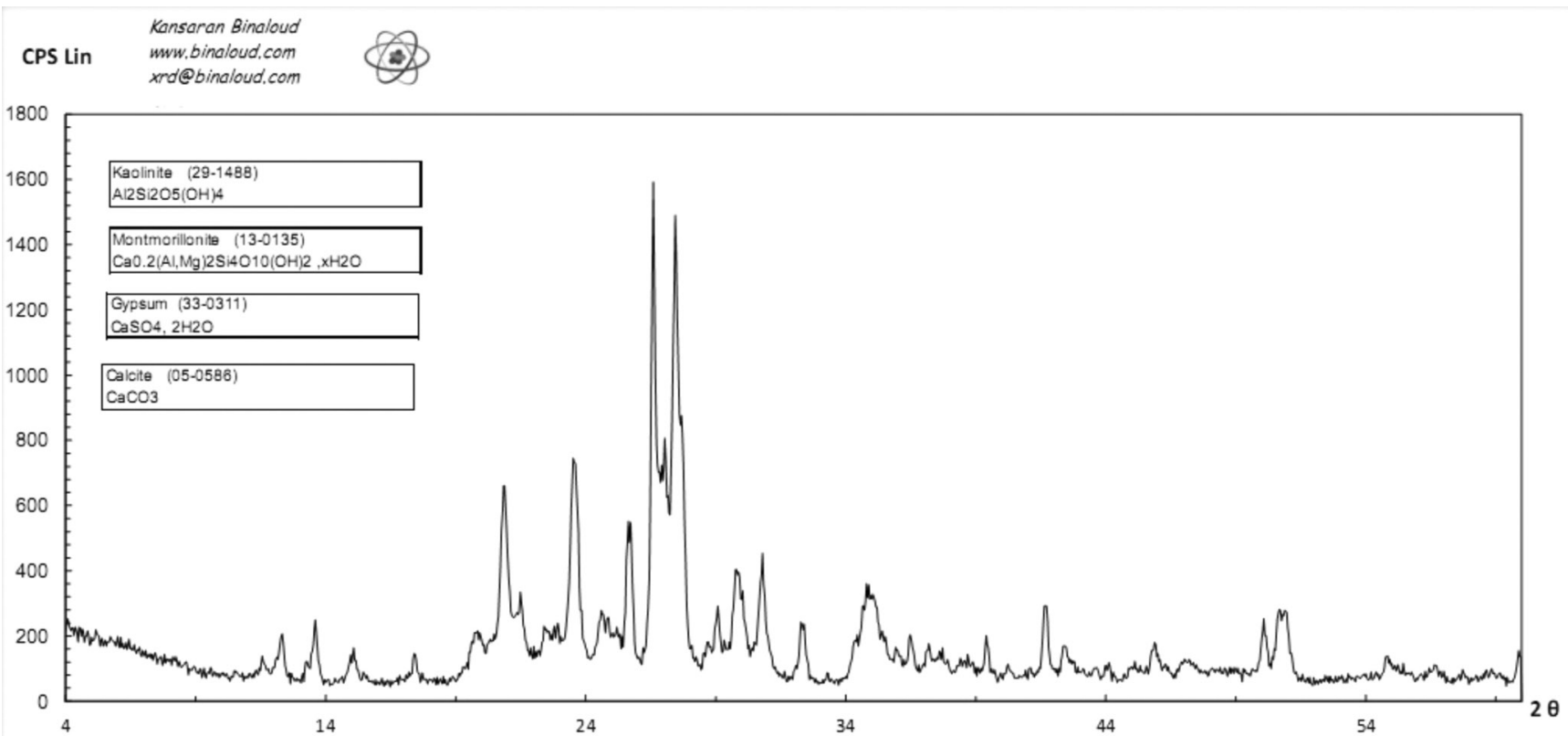

Figure 5. Sample No.1 XRD spectra diagram, showing clay, chalk and calcite minerals.

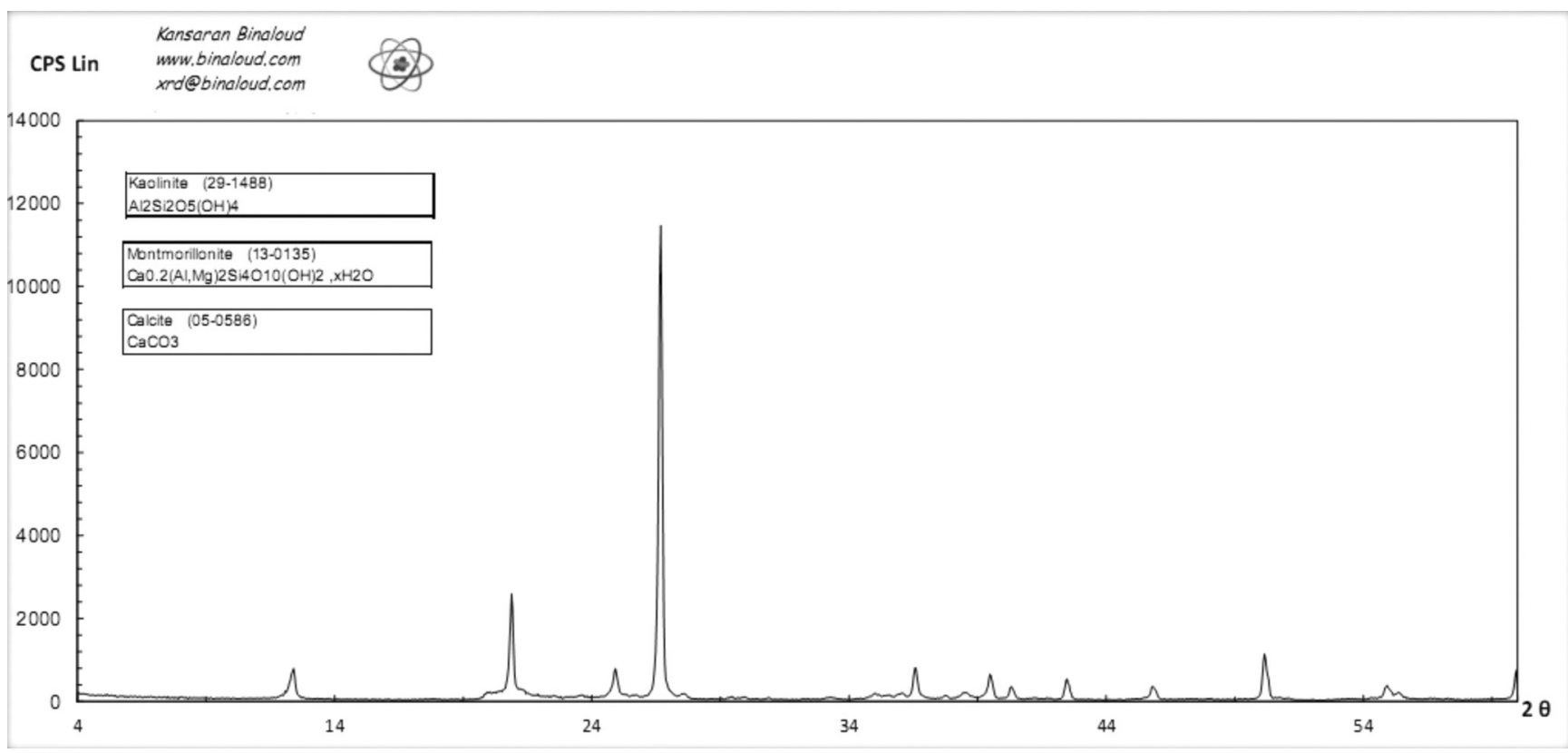

Figure 6. Sample No.2 XRD spectra diagram, showing kaolinite, montmorillonite and calcite minerals.

temperatures, as different minerals are destroyed or begin to form at different temperatures. XRD is also commonly used in the study of corrosion products formed on the surface of metals, including iron and copper alloys.

Three samples were sent to the Kansaran Binaloud laboratory for analysis. When pottery is exposed to different temperatures, it shows different and distinct physical and chemical changes. Normally, the water and moisture of the pottery evaporates at a temperature of 100 to $200^{\circ} \mathrm{C}$. At a temperature of 250 to $450^{\circ} \mathrm{C}$, the organic materials in the pottery burn. Finally, at a temperature of 700 to $800^{\circ} \mathrm{C}$, the calcium carbonate in the clay decomposes and turns into calcium oxide and carbon dioxide. Conventionally, this is the proper temperature for producing good quality pottery. At $850^{\circ} \mathrm{C}$, the pottery only contains quartz and feldspar. At temperatures above 850 to $950^{\circ} \mathrm{C}$, a baking process occurs which leads to the emergence of pyroxene besides the quartz and feldspar in the pottery. In these samples, no sign of calcium carbonate or calcium oxide are found.

Examination of these samples showed that the calcite mineral $\left(\mathrm{CaCO}_{3}\right)$ did not decompose when heated and did not convert to $\mathrm{CaO}$ and $\mathrm{CO}_{2}$. Therefore, the maximum identified temperature is around $700^{\circ} \mathrm{C}$. There exist a number of clay minerals in the texture of all the samples, each one indicating a different temperature. The presence of clay minerals usually depends on the type of soil used to make the pottery. 
Figure 7. Analysed samples.

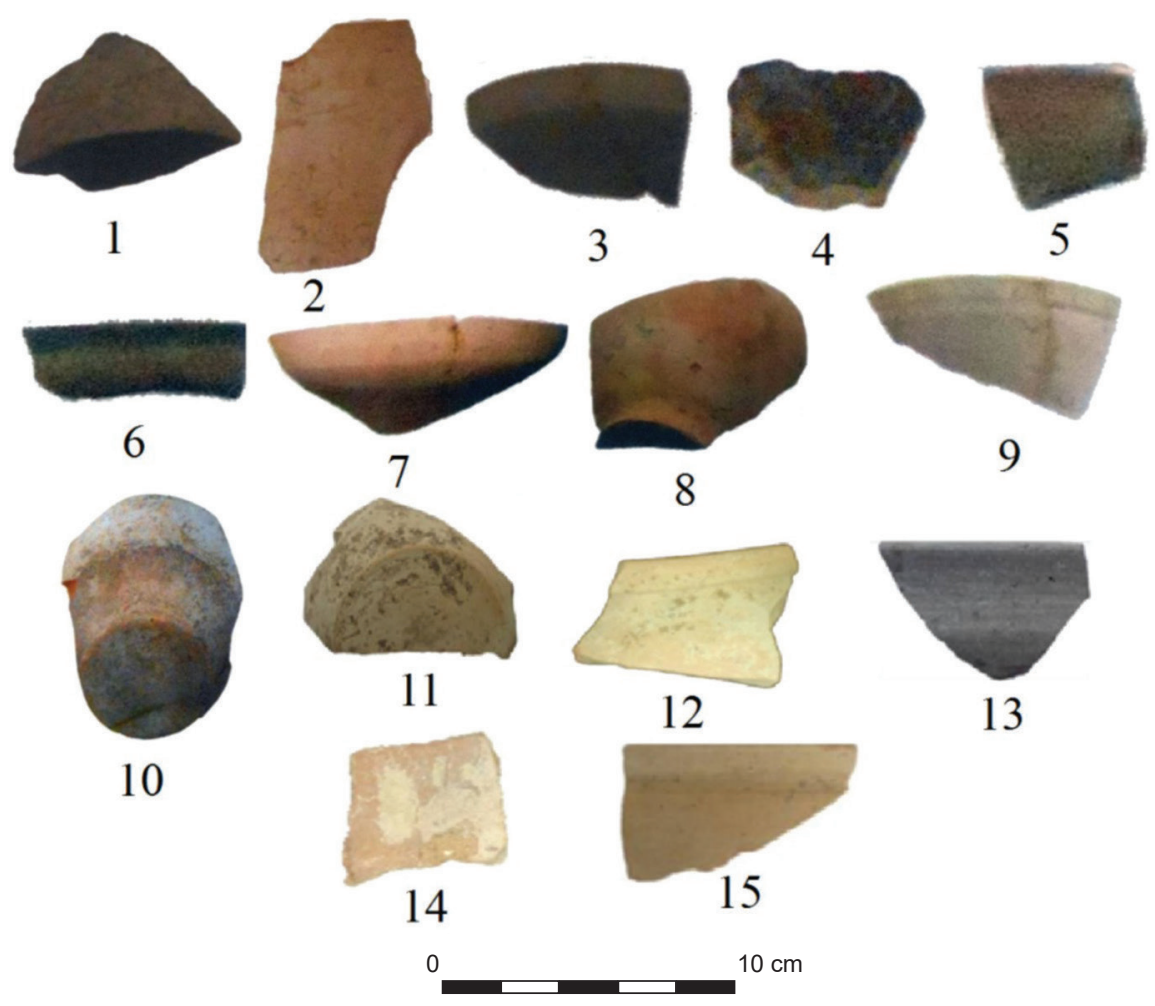

Table 1. General data of samples.

\begin{tabular}{|c|c|c|c|c|c|c|c|c|c|c|c|}
\hline $\begin{array}{c}\text { Sample } \\
\text { No. }\end{array}$ & Section & Technique & Heating & $\begin{array}{c}\text { Interior } \\
\text { colour }\end{array}$ & $\begin{array}{c}\text { Exterior } \\
\text { colour }\end{array}$ & $\begin{array}{l}\text { Paste } \\
\text { colour }\end{array}$ & Design & $\begin{array}{c}\text { Height } \\
\text { cm }\end{array}$ & $\begin{array}{l}\text { Thick } \\
\text { mm }\end{array}$ & $\begin{array}{c}\text { Diametr } \\
\mathrm{cm}\end{array}$ & Temper \\
\hline 1 & base & wheel made & complete & red & buff & red & - & 3.5 & 17 & 9 & mineral \\
\hline 2 & lip & wheel made & complete & buff & buff & red & - & 9.0 & 7 & 10 & mineral \\
\hline 3 & lip & wheel made & complete & buff & buff & red & - & 3.7 & 4 & 13 & mineral \\
\hline 4 & lip & wheel made & complete & buff & buff & red & - & 5.1 & 4 & 16 & mineral \\
\hline 5 & body & wheel made & complete & red & red & red & geometric & 3.3 & 14 & - & mineral \\
\hline 6 & lip & wheel made & complete & buff & buff & red & - & 7.0 & 5 & 20 & mineral \\
\hline 7 & base & wheel made & complete & red & red & buff & - & 7.0 & 10 & 9 & mineral \\
\hline 8 & $\operatorname{lip}$ & wheel made & complete & red & red & red & - & 4.0 & 6 & 29 & mineral \\
\hline 9 & lip & wheel made & complete & buff & buff & red & - & 4.0 & 9 & 21 & mineral \\
\hline 10 & lip & wheel made & complete & buff & buff & red & - & 8.0 & 4 & 24 & mineral \\
\hline 11 & base & wheel made & complete & buff & buff & red & - & 17.5 & 10 & 12 & mineral \\
\hline 12 & base & wheel made & complete & buff & buff & buff & - & 50.0 & 8 & 8 & mineral \\
\hline 13 & lip & wheel made & complete & red & buff & red & - & 67.0 & 6 & 8 & mineral \\
\hline 14 & lip & wheel made & complete & buff & buff & red & - & 45.0 & 6 & 15 & mineral \\
\hline 15 & lip & wheel made & complete & red & red & red & - & 37.0 & 5 & 20 & mineral \\
\hline
\end{tabular}

Clay minerals are derived from the chemical decomposition of rocks containing high levels of feldspar, a phenomenon that is called argillic alteration in geology. The result of these changes is the formation of clay deposits that are important sources depending on their type of minerals, presence of impurities, etc. Probably the soil used for the pottery production contained a mixture of lime and clay with impurities such as gypsum. Due to the presence of clay minerals in the pottery's soil and the temperature for baking the pottery, the existent clay in the soil is sufficient.

\subsection{XRF Test}

$\mathrm{XRF}$ analysis has become a routine technique in investigations of elemental composition for a wide variety of archaeological materials. In archaeology, the main application of EDXRF is for the rapid identification and semi-quantitative analysis of a wide range of materials including metals and their alloys, ceramics, glass, jet, faience, pigments, glazes, gemstones, and industrial debris (Pollard et al., 2007, p.118).

For this method, 15 samples were sent to the XRF laboratory of Tarbiat Modares University and analyzed by a 
Table 2. Chemical composition (\%) of the samples under study (sum of elements is not $100 \%$ ).

\begin{tabular}{|c|c|c|c|c|c|c|c|c|c|c|c|c|}
\hline SampleNo & $\begin{array}{c}\mathrm{SiO}_{2} \\
\%\end{array}$ & $\begin{array}{c}\mathrm{Al}_{2} \mathrm{O}_{3} \\
\%\end{array}$ & $\begin{array}{c}\mathrm{Fe}_{2} \mathrm{O}_{3} \\
\%\end{array}$ & $\begin{array}{c}\mathrm{CaO} \\
\% \\
\end{array}$ & $\begin{array}{c}\mathrm{Na}_{2} \mathrm{O} \\
\% \\
\end{array}$ & $\begin{array}{c}\mathbf{K}_{2} \mathbf{O} \\
\% \\
\end{array}$ & $\begin{array}{c}\text { MgO } \\
\% \\
\end{array}$ & $\begin{array}{c}\mathrm{TiO}_{2} \\
\%\end{array}$ & $\begin{array}{c}\mathrm{MnO} \\
\% \\
\end{array}$ & $\begin{array}{c}\mathbf{P}_{2} \mathbf{O}_{5} \\
\%\end{array}$ & $\begin{array}{l}\mathrm{S} \\
\% \\
\end{array}$ & $\begin{array}{c}\text { Loss on ignition } \\
\% \\
\end{array}$ \\
\hline 1 & 54.01 & 5.9 & 15.11 & 8.24 & 1.28 & 2.83 & 1.20 & 1.701 & 0.070 & 0.701 & 0.001 & 5.98 \\
\hline 2 & 52.65 & 5.51. & 13.17 & 10.51 & 0.31 & 1.48 & 1.83 & 2.383 & 0.143 & 0.251 & 0.002 & 7.10 \\
\hline 3 & 53.11 & 5.26 & 15.76 & 9.32 & 1.03 & 1.21 & 1.61 & 1.231 & 0.094 & 0.652 & 0.004 & 5.77 \\
\hline 4 & 50.98 & 3.72 & 14.43 & 13.72 & 1.89 & 1.03 & 1.42 & 1.201 & 0.120 & 0.45 & 0.003 & 7.75 \\
\hline 5 & 55.11 & 5.6 & 14.13 & 7.24 & 1.08 & 2.12 & 1.07 & 1.60 & 0.021 & 0.311 & 0.001 & 6.38 \\
\hline 6 & 51.55 & 5.33. & 14.17 & 11.82 & 0.11 & 1.65 & 1.43 & 2.435 & 0.109 & 0.437 & 0.004 & 7.10 \\
\hline 7 & 52.21 & 4.12 & 13.9 & 10.15 & 0.27 & 1.30 & 1.63 & 2.215 & 0.136 & 0.532 & 0.003 & 6.96 \\
\hline 8 & 52.33 & 3.95 & 12.73 & 12.80 & 0.81 & 1.27 & 1.12 & 1.63 & 0.120 & 0.52 & 0.011 & 7.62 \\
\hline 9 & 53.12 & 5.1 & 14.98 & 9.78 & 1.48 & 1.83 & 1.65 & 1.130 & 0.062 & 0.661 & 0.002 & 5.63 \\
\hline 10 & 54.01 & 6.12 & 14.21 & 8.24 & 1.28 & 2.83 & 1.20 & 1.701 & 0.061 & 0.621 & 0.001 & 6.82 \\
\hline 11 & 53.68 & 2.73 & 13.33 & 12.72 & 1.19 & 1.04 & 1.32 & 1.26 & 0.131 & 0.361 & 0.003 & 7.52 \\
\hline 12 & 53.01 & 5.76 & 13.45 & 11.32 & 0.87 & 1.34 & 1.19 & 1.613 & 0.068 & 0.751 & 0.002 & 5.68 \\
\hline 13 & 54.78 & 3.72 & 13.02 & 13.72 & 0.74 & 1.14 & 0.96 & 1.52 & 0.342 & 0.861 & 0.001 & 7.58 \\
\hline 14 & 53.28 & 4.76 & 13.31 & 12.74 & 0.75 & 1.13 & 1.81 & 1.181 & 0.203 & 0.371 & 0.003 & 6.56 \\
\hline 15 & 56.01 & 3.39 & 15.19 & 10.64 & 1.36 & 2.09 & 1.73 & 1.126 & 0.172 & 0.598 & 0.001 & 5.63 \\
\hline
\end{tabular}

Table 3. Elements in samples under study (ppm).

\begin{tabular}{crrrrrrrrrrrrrrrrrrrrrrrrrrrr}
\hline Sample No. & $\mathbf{C l}$ & $\mathbf{B a}$ & $\mathbf{S r}$ & $\mathbf{C u}$ & $\mathbf{Z n}$ & $\mathbf{P b}$ & $\mathbf{N i}$ & $\mathbf{C r}$ & $\mathbf{V}$ & $\mathbf{C e}$ & $\mathbf{L a}$ & $\mathbf{W}$ & $\mathbf{Z r}$ & $\mathbf{Y}$ & $\mathbf{R b}$ & $\mathbf{C o}$ & $\mathbf{A s}$ & $\mathbf{U}$ & $\mathbf{T h}$ & $\mathbf{M o}$ & $\mathbf{G a}$ & $\mathbf{N b}$ \\
\hline 1 & 61 & 175 & 243 & 13 & 110 & 11 & 40 & 14 & 18 & 53 & 19 & 7 & 203 & 32 & 49 & 2 & 8 & 1 & 3 & 26 & 17 & 10 \\
2 & 101 & 152 & 178 & 29 & 102 & 16 & 42 & 7 & 22 & 46 & 17 & 4 & 219 & 42 & 56 & 2 & 9 & 2 & 1 & 16 & 18 & 13 \\
3 & 73 & 178 & 240 & 16 & 108 & 15 & 48 & 18 & 20 & 48 & 21 & 5 & 213 & 30 & 29 & 3 & 7 & 2 & 3 & 23 & 16 & 13 \\
4 & 79 & 310 & 160 & 27 & 130 & 24 & 26 & 3 & 70 & 113 & 38 & 1 & 289 & 69 & 119 & 2 & 83 & 1 & 2 & 8 & 19 & 9 \\
5 & 85 & 173 & 249 & 19 & 114 & 15 & 52 & 15 & 18 & 58 & 17 & 9 & 231 & 42 & 50 & 2 & 7 & 2 & 3 & 22 & 17 & 12 \\
6 & 109 & 129 & 182 & 33 & 114 & 14 & 48 & 1 & 24 & 42 & 16 & 4 & 227 & 39 & 52 & 1 & 9 & 1 & 4 & 15 & 16 & 12 \\
7 & 93 & 202 & 170 & 30 & 128 & 19 & 31 & 8 & 42 & 61 & 25 & 5 & 251 & 52 & 72 & 2 & 32 & 2 & 3 & 5 & 19 & 18 \\
8 & 92 & 167 & 213 & 15 & 118 & 8 & 39 & 17 & 19 & 34 & 15 & 7 & 180 & 32 & 48 & 3 & 9 & 3 & 5 & 18 & 15 & 11 \\
9 & 97 & 190 & 177 & 14 & 118 & 9 & 33 & 9 & 46 & 64 & 21 & 4 & 240 & 59 & 69 & 2 & 29 & 3 & 2 & 4 & 17 & 8 \\
10 & 96 & 128 & 190 & 27 & 119 & 10 & 40 & 2 & 21 & 50 & 18 & 6 & 210 & 43 & 52 & 3 & 8 & 1 & 2 & 16 & 12 & 13 \\
11 & 80 & 309 & 158 & 30 & 140 & 28 & 24 & 2 & 73 & 110 & 42 & 2 & 293 & 72 & 114 & 3 & 79 & 2 & 1 & 9 & 18 & 8 \\
12 & 105 & 137 & 183 & 36 & 120 & 16 & 47 & 10 & 19 & 39 & 19 & 5 & 217 & 41 & 56 & 2 & 12 & 1 & 1 & 15 & 16 & 13 \\
13 & 74 & 183 & 236 & 19 & 119 & 12 & 39 & 9 & 20 & 54 & 21 & 3 & 210 & 39 & 53 & 2 & 10 & 2 & 3 & 19 & 19 & 14 \\
14 & 98 & 149 & 182 & 366 & 115 & 13 & 41 & 8 & 22 & 43 & 17 & 4 & 213 & 49 & 59 & 1 & 14 & 2 & 2 & 17 & 18 & 12 \\
15 & 83 & 316 & 157 & 26 & 138 & 24 & 19 & 2 & 80 & 98 & 39 & 3 & 279 & 81 & 135 & 2 & 81 & 1 & 2 & 9 & 17 & 7 \\
\hline
\end{tabular}

Phillips XRF machine (Model 2404). This machine has the ability to detect elements up to a one millionth part (ppm). The samples were crushed into powder and then placed in the machine for testing. The results of the experiments are listed in Tables 2 \& 3 below.

\section{Discussion}

Although our collection for XRD (3 samples) is very small and we could not interpret its results as a reliable and definitive outcome, the existence of montmorillonite in Sample 3 can be considered as an indication of the local production of this pottery. Montmorillonite is the main constituent of bentonite that was a hair-cleaner clay used in traditional healthcare that is also referred to as Neyshaburi or Khorasani clay in the Persian Language. Based on some historical sources, this clay was used not only for cleaning but also for eating (Nuiri, 2007).
As Alikhani, Shamanian and Jafari Zanglanlo have reported in their article, montmorillonite is found south of Neyshabour at Tajroud's geological section (Alikhani, Shamanian and Jafari Zanglanlo, 2014). They also reported that the calcite in this region was created due to hydrothermal alteration. The presence of calcite shows the temperate of the kiln was not above $800^{\circ} \mathrm{C}$.

The XRF analysis prepared comprehensive data about the main chemical elements in the pottery samples. This data does not sum to one hundred percent. In the XRF method, the main constitutive elements and their ratios were selected for a better understanding. One of these groups is the proportion of nickel/vanadium and barium/rubidium; these ratios were then compared in the software. The results were put in a chart using the Dplot software (Figure 8). As can be seen, the findings on this diagram show at least one main source (A) and two other possible sub-sources. For more certainty, the results were compared to the ratio of cerium/ 


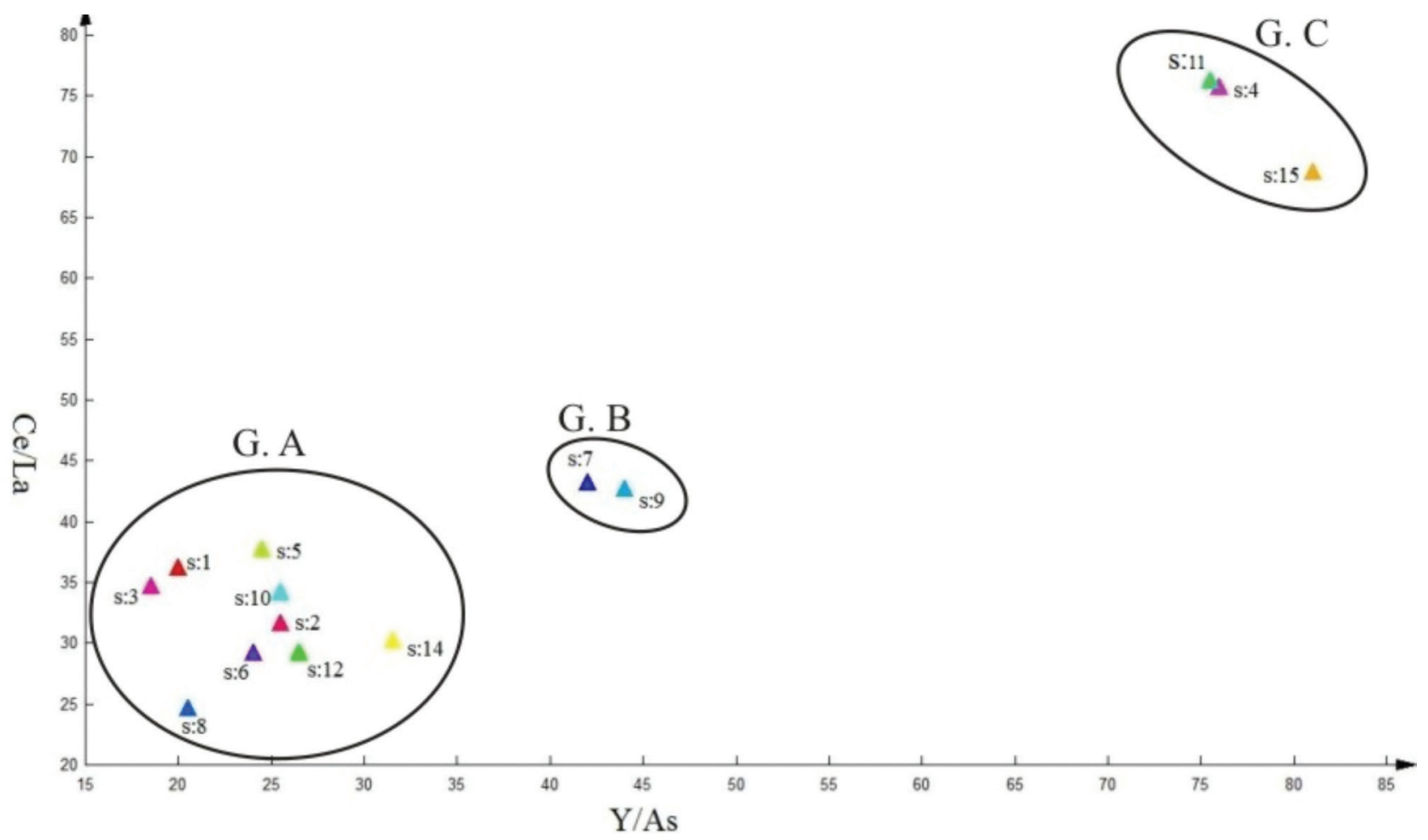

Figure 8. Ratio of $\mathrm{Ni} / \mathrm{V}$ to $\mathrm{Br} / \mathrm{Rb}$ elements.

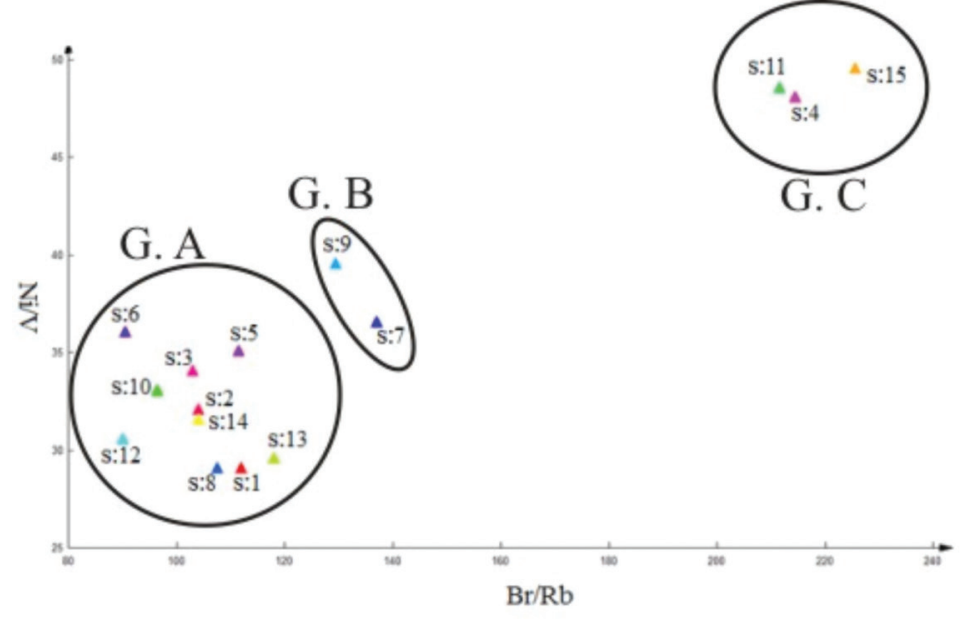

Figure 9. Ratio of $\mathrm{Ce} / \mathrm{La}$ to $\mathrm{Y} / \mathrm{As}$ elements.

lanthanum to yttrium/arsenic and again were estimated using the Dplot software which confirmed the results of the previous comparison (Figure 9). The result shows that the same samples that are in group A in Figure 8 are also in group A in Figure 9. This situation is repeated for the other groups.

The results show that the main source was probably located near the site (not to mention inside the site) that was the major supply of the pottery found in the area. However, different clay qualities were also identified in several pottery pieces indicating that some of the pottery was imported as a result of commercial interactions (at the moment, nothing more can be said about them being distant or close interactions).

\section{Conclusion}

Based on the experiments carried out on the clay samples, the presence of clay mines around the site, and the geological structure of Neyshabur, most of the potteries were local productions. The presence of montmorillonite (bentonite) in Sample 3 that was identified with the XRD testing shows that the sample originated from the Neyshabur geological region.

Assuming the locality of the BMAC potteries as being found in the Shahrake Firouzeh site, one can argue that the significant differences that were found in the composition of samples B and C, though very small, could indicate different sources of clay that were imported from other areas. It is 
possible that based on the texture and nature of the area, which is a cemetery, the samples were burial gifts that were placed in the graves by relatives who lived in neighbouring areas. However, the authors consider this idea only a possibility. In future studies, along with the analysis of more BMAC samples, soil samples from the area should be analyzed with the same methods used in this study in order to obtain a more accurate pattern of the possible clay extraction sources. Also, samples should be studied using petrography and thin-section preparation to compare the minerals in the pottery with the geological structure of the area.

\section{References}

BANGHANI, M.A., SHAMANIAN, G.H., ZANGLANLOU, M.J., 2014. Mineralization and hydrothermal alteration of Tajroud section. Journal of Economic Geology, 2(15), 325-339.

BASAFA, H., 2011. Preliminary report on second season of archaeological excavation at Sahrake Firouzeh. Unpublished report to the Iranian cultural heritage, handicraft and tourism.

BASAFA, H., NOBARI, A.H., SHAHIDI, H.K., NEYESTANI, J., 2014. Effect of hydrology on formation of Shahrake Firouzeh prehistoric site in Neyshabur plain (in Persian). Journal of Environmental Research, 5(9), 73-78.

BASAFA, H., RAHMATI, M., 2014. Third salvage excavation in Shahrake Firouzeh, Neyshabur (in Persian). In: Short Articles from Iranian Twelfth Annual Congress. Teheran: Iranian cultural heritage, handicraft and tourism.

GILlMORE, G.K., CONINGHAM, R.A.E., FAZELI, H., YOUNG, R., MAGHSOUDI M., BATT C.M., RUSHWORTH, G., 2009. Irrigation on the Tehran Plain, Iran: Tepe Pardis - The site of a Possible Neolithic Irrigation Feature? Catena, 78, 285-300.

GILLMORE, G.K., STEVENSE, T., BUYKEART, J.P., CONINGHAM, R.A.E., BATT, C., FAZELI, H., YOUNG, R., MAGHSOUDI, M., 2011. Geoarchaeology and the Value of Multidisciplinary Palaeoenvironmental Approaches: A Case Study from the Tehran Plain, Iran. In: Geological Society, London, Special Publications, 352, 49-67.

KHADEMI, N.F., REZAIE, A., NOBARI, A. H., ZADEH, M.F., 2010 XRF analysis on Shoshtar Palin's Holocene deposits to recognizing the prehistoric sites (in Persian). Journal of Social Science Knowledge, 4(1), 170-181.

LENG, Y., 2008. Materials Characterization Introduction to Microscopic and Spectroscopic Methods. Singapore: John Wiley \& Sons (Asia).

MAJIDZADEH, Y., 1991. Archaeology and pottery (in Persian). Journal of archaeology and history, 10, 4-13.

MIROSCHEDJI, P.D.E., 1973. Vases et objets en steatite susiens du Musee du Louvre. Cahiers de la Délégation Archéologique Française en Iran, 2, 9-77.

NIKNAMI, K., REZAIE, I., 2013. Elemental analysis on chalcolithic period soils of Tape Zagheh to finding the special works (in Persian). Journal of archaeological research 5(2), 163-182.

NOWEIRY, S.A.A., 2007. Nahayat alarb fi fonon aladab (in Persian). Translated to Persian by Mahmoud Mahdavi Damghani. Tehran: Amir Kabir Publication.

SARIANIDI, V.I., 1998. Margiana and Protozoroastrism. Athens: Kapon Editions.

SHAHROKHI, S.R., 2006. Recognizing the obsidian sources of Sharyeri site, Ardebil by XRF. Unpublished thesis (MA). Tarbiat Modares University.

TALAI, H., 2012. Bronze Age of Iran (in Persian). Tehran: Samt.

TALAI, H., ALIYARI, A., ZOGHI, Y., 2009. Technological Study of the Fifth Millennium B.C. Pottery in North-Center Iran by XRF and XRD (in Persian). Journal of Archaeological Research, 1(1), 65-84. 